\title{
Lysinimicrobium mangrovi gen. nov., sp. nov., an actinobacterium isolated from the rhizosphere of a mangrove
}

Correspondence

Moriyuki Hamada

hamada-moriyuki@nite.go.jp

\author{
Moriyuki Hamada, ${ }^{1,2}$ Tomohiko Tamura, ${ }^{1}$ Hideki Yamamura, ${ }^{2}$ \\ Ken-ichiro Suzuki ${ }^{1}$ and Masayuki Hayakawa ${ }^{2}$ \\ ${ }^{1}$ NITE Biological Resource Center (NBRC), National Institute of Technology and Evaluation, \\ 2-5-8 Kazusakamatari, Kisarazu, Chiba 292-0818, Japan \\ ${ }^{2}$ Division of Applied Biological Sciences, Interdisciplinary Graduate School of Medicine and \\ Engineering, University of Yamanashi, Takeda-4, Kofu, Yamanashi 400-8511, Japan
}

\begin{abstract}
A novel strain of Gram-staining-positive bacterium, designated $\mathrm{HIO8}^{-69^{\top}}$, was isolated from the rhizosphere of a mangrove on Iriomote Island, Japan, and its taxonomic position was investigated by a polyphasic approach. The strain had peptidoglycan of the $A 4 \alpha$ type, with lysine as the diagnostic diamino acid. The predominant menaquinone was demethylmenaquinone DMK-9 $\left(\mathrm{H}_{4}\right)$ and the major fatty acids were anteiso- $C_{15: 0}$, anteiso- $C_{17: 0}$ and $C_{16: 0}$. The major polar lipids were diphosphatidylglycerol, phosphatidylglycerol, phosphatidylinositol and an unidentified polar lipid but minor amounts of other polar lipids were also detected. The genomic DNA $\mathrm{G}+\mathrm{C}$ content of strain HI08-69 ${ }^{\top}$ was 71.7 mol\%. In phylogenetic analyses based on 16S rRNA gene sequences, the novel strain and members of the genus Demequina formed a monophyletic cluster, with pairwise sequence similarities of 95.6-96.8\%. However, strain HI08-69 ${ }^{\top}$ was clearly distinguishable from all established members of the genus Demequina in terms of several chemotaxonomic characteristics. On the basis of the phenotypic and genotypic characteristics, strain HI08-69 ${ }^{\top}$ represents a novel species in a new genus for which the name Lysinimicrobium mangrovi gen. nov., sp. nov. is proposed. The type strain of the type species is HI08-69 ${ }^{\top}$ $\left(=\right.$ NBRC $105856^{\top}=$ DSM $\left.24868^{\top}\right)$.
\end{abstract}

The family Demequinaceae, which was proposed by Ue et al. (2011), currently contains just one genus: Demequina (Yi et al., 2007). At the time of writing, the genus Demequina consists of six recognized species, all of which have demethylmenaquinone DMK- $9\left(\mathrm{H}_{4}\right)$ as their diagnostic isoprenoid quinone and a cell-wall peptidoglycan of the A4 $\beta$ type (Schleifer \& Kandler, 1972). During the course of a study of bacterial diversity in cool-temperate and subtropical areas, a novel actinobacterium was isolated from a soil sample collected from the rhizosphere of a tree on a subtropical island in Japan. Comparative 16S rRNA gene sequence analysis indicated that the isolate, which was designated strain HI08-69 ${ }^{\mathrm{T}}$, is a member of the suborder Micrococcineae. In the present study, the taxonomic position of this strain was determined by using a polyphasic approach.

Strain HI08-69 ${ }^{\mathrm{T}}$ was isolated from a soil sample that had been collected from the rhizosphere of a mangrove (Bruguiera

The GenBank/EMBL/DDBJ accession number for the $16 \mathrm{~S}$ rRNA gene sequence of strain $\mathrm{HIO8}-69^{\top}$ is $\mathrm{AB} 639012$.

A supplementary figure is available with the online version of this paper. gymnorhiza) growing on Iriomote Island, Okinawa, Japan. Approximately $1 \mathrm{~g}$ of the sample was diluted 10-, 100- and 1000 -fold with saline before $0.2 \mathrm{ml}$ of each dilution was spread on plates of $0.2 \times$ NBRC medium $802[0.2 \%(\mathrm{w} / \mathrm{v})$ polypeptone, $0.04 \%(\mathrm{w} / \mathrm{v})$ yeast extract, $0.02 \%(\mathrm{w} / \mathrm{v})$ $\mathrm{MgSO}_{4} \cdot 7 \mathrm{H}_{2} \mathrm{O}$ and $1.5 \%(\mathrm{w} / \mathrm{v})$ agar; at $\left.\mathrm{pH} 7.0\right]$ supplemented with $5.0 \%(\mathrm{w} / \mathrm{v}) \mathrm{NaCl}, 0.005 \%$ (w/v) cycloheximide and $0.002 \%(\mathrm{w} / \mathrm{v})$ nalidixic acid. After cultivation at $30{ }^{\circ} \mathrm{C}$ for 1 week and repeated isolation, strain $\mathrm{HI} 08-69^{\mathrm{T}}$ was obtained. As strain HI08-69 ${ }^{\mathrm{T}}$ did not require $\mathrm{NaCl}$ for growth, fullstrength NBRC medium 802 [1.0\% (w/v) polypeptone, $0.2 \%$ $(\mathrm{w} / \mathrm{v})$ yeast extract, $0.1 \%(\mathrm{w} / \mathrm{v}) \quad \mathrm{MgSO}_{4} \cdot 7 \mathrm{H}_{2} \mathrm{O}$ and, if required, $1.5 \%(\mathrm{w} / \mathrm{v})$ agar; at $\mathrm{pH} 7.0$ ] was used as the basal medium for this study. Biomass for all of the chemotaxonomic and molecular systematic studies except the fatty acid analysis was obtained by incubating the novel strain in shake flasks at $28{ }^{\circ} \mathrm{C}$ and 100 r.p.m. for $48 \mathrm{~h}$.

Colony appearance and pigment production were investigated after incubation at $28{ }^{\circ} \mathrm{C}$ for 3 days. The morphology of cells cultured for up to 7 days was determined under a light microscope (BX-51; Olympus) and in a scanning electron microscope (JSM-6060; JEOL). Cell motility, $\mathrm{pH}$ 
range for growth, $\mathrm{NaCl}$ tolerance, anaerobic growth, Gram staining and oxidase activity were determined using the methods outlined by Hamada et al. (2010). The temperature range and optimum temperature for growth were determined by incubating the novel strain at $5,10,15,20$, $25,28,37,45$ and $60{ }^{\circ} \mathrm{C}$ on plates of NBRC medium 802 agar for 4 days. Growth at 5 and $10{ }^{\circ} \mathrm{C}$ was also evaluated after 14 days of incubation. Other physiological and biochemical tests were performed using API ZYM, API Coryne, API 20E and API 50CH strips (bioMérieux) according to the manufacturer's instructions.

After incubation at $28{ }^{\circ} \mathrm{C}$ for 3 days, strain HI08-69 formed pale yellow, circular, transparent, smooth colonies with diameters of $0.5-1.0 \mathrm{~mm}$. Pigment production was not observed. The cells were Gram-staining-positive, nonmotile and non-spore-forming and exhibited a rod-tococcus growth cycle. Cells of exponentially growing cultures were rod-shaped $(0.4-0.6 \times 1.0-3.0 \mu \mathrm{m})$, whereas stationary phase cells were oval to coccoid $(0.5-0.6 \times 0.5-$ $1.0 \mu \mathrm{m}$ ) (Fig. 1). The cells were seen to fragment by the formation of septa. Growth occurred at $15-28{ }^{\circ} \mathrm{C}$ (optimum $28{ }^{\circ} \mathrm{C}$ ) and $\mathrm{pH} 6.0-9.0$ (optimum between $\mathrm{pH} 7.0$ and $\mathrm{pH}$ 8.0). The strain exhibited good growth with $\mathrm{NaCl}$ concentrations of $0-5 \%(\mathrm{w} / \mathrm{v})$ and moderate growth with $7 \%(\mathrm{w} / \mathrm{v})$; no growth was observed with $\mathrm{NaCl}$ at 10 or $15 \%(\mathrm{w} / \mathrm{v})$. Optimal growth occurred in the absence of $\mathrm{NaCl}$. Weak growth was observed under anaerobic conditions. The results of other physiological and biochemical analyses have been summarized in the species description.

The PCR-based amplification and sequencing of the $16 \mathrm{~S}$ rRNA gene of strain HI08-69 ${ }^{\mathrm{T}}$ were performed as described previously (Hamada et al., 2010). The novel strain's phylogenetic neighbours were identified and pairwise $16 \mathrm{~S}$ rRNA gene sequence similarities were calculated, using the EzTaxon server (Chun et al., 2007). The CLUSTAL_X program (Thompson et al., 1997) was used to align the almostcomplete 16S rRNA gene sequence of strain HI08- $69^{\mathrm{T}}$ with the corresponding sequences of members of the genus Demequina and some related taxa. Phylogenetic trees were constructed using the neighbour-joining (Saitou \& Nei, 1987), maximum-likelihood (Felsenstein, 1981) and maximum-parsimony (Fitch, 1971) algorithms and version 5.01 of the MEGA program (Tamura et al., 2011). The resultant tree topologies were evaluated by bootstrap analysis (Felsenstein, 1985) based on 1000 replicates. In the trees, strain HI08- $69^{\mathrm{T}}$ formed a clade with members of the genus Demequina (Fig. 2) although 16S rRNA gene sequence similarities of only $95.6-96.8 \%$ were recorded in the pairwise comparisons between the novel strain and the type strain of each Demequina species.

A cell-wall sample was prepared, from approximately $1 \mathrm{~g}$ wet cells of the novel strain, by mechanical disruption with an ultrasonic oscillator and glass beads and then differential centrifugation in distilled water. The sample of cell walls was purified by boiling in $4 \%(\mathrm{w} / \mathrm{v})$ SDS for $40 \mathrm{~min}$,
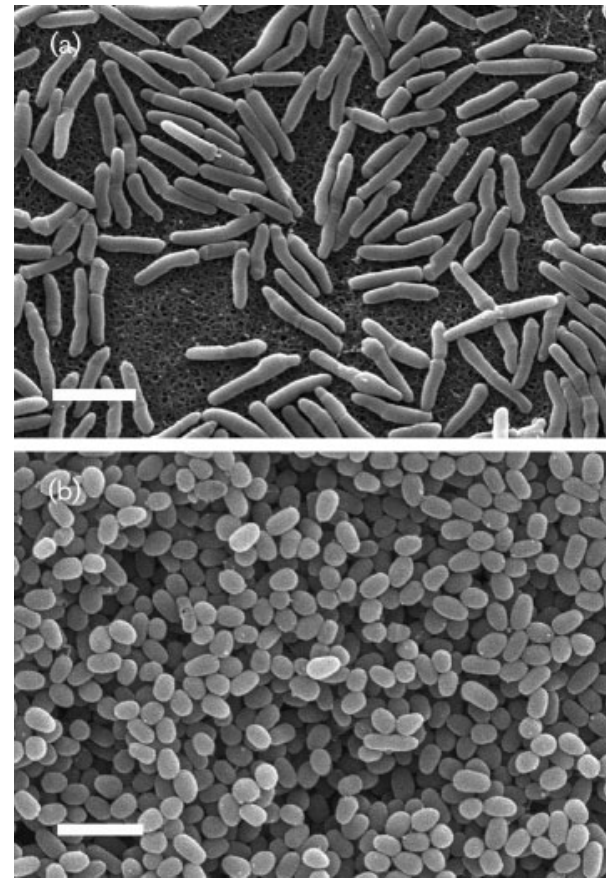

Fig. 1. Scanning electron micrographs of cells of strain HIO8-69 grown on NBRC medium 802 for 1 (a) and 7 (b) days at $28{ }^{\circ} \mathrm{C}$. Bars, $2 \mu \mathrm{m}$.

washed several times with distilled water and then hydrolysed in $4 \mathrm{M} \mathrm{HCl}$ for $16 \mathrm{~h}$. The molar ratios of the amino acids in the resultant hydrolysate were determined according to the method described by Hamada et al. (2010). The amino acid isomers in the same hydrolysate were determined by LC-MS as described by Nozawa et al. (2007), in an LCMS-2020 spectrometer (Shimadzu). Biomass for the investigation of cellular fatty acids was grown on tryptic soy agar (Difco) for $24 \mathrm{~h}$ at $28{ }^{\circ} \mathrm{C}$. Cellular fatty acid methyl esters were prepared from the biomass and analysed by following the standard protocol of version 4.0 of the Sherlock Microbial Identification System (MIDI) and using version 4.0 of the TSBA database (Sasser, 1990) and a $6890 \mathrm{~N}$ GC (Agilent). Polar lipids were analysed by TLC, as described by Hamada et al. (2010), using chloroform-methanol-water $(65: 25: 4, \mathrm{v} / \mathrm{v} / \mathrm{v})$ in the first direction and chloroform-acetic acid-methanol-water $(80: 18: 12: 5, \mathrm{v} / \mathrm{v} / \mathrm{v} / \mathrm{v})$ in the second. Isoprenoid quinones, cell-wall sugars and genomic DNA G $+\mathrm{C}$ content were investigated by the methods outlined by Hamada et al. (2010).

The peptidoglycan of strain HI08-69 $9^{\mathrm{T}}$ contained alanine (Ala), glutamic acid (Glu), serine (Ser) and lysine (Lys) in a molar ratio of $1.0: 2.0: 1.0: 0.8$. Enantiomeric analysis of the peptidoglycan amino acids revealed the presence of $\mathrm{D}$ Ala, D-Glu, L-Ser and L-Lys but no L-Ala. These results indicate that the cell-wall peptidoglycan of strain HI08-69 ${ }^{\mathrm{T}}$ is of the A4 $\alpha$ type (Schleifer \& Kandler, 1972) with an interpeptide bridge comprising D-Glu, and an L-Ser residue 


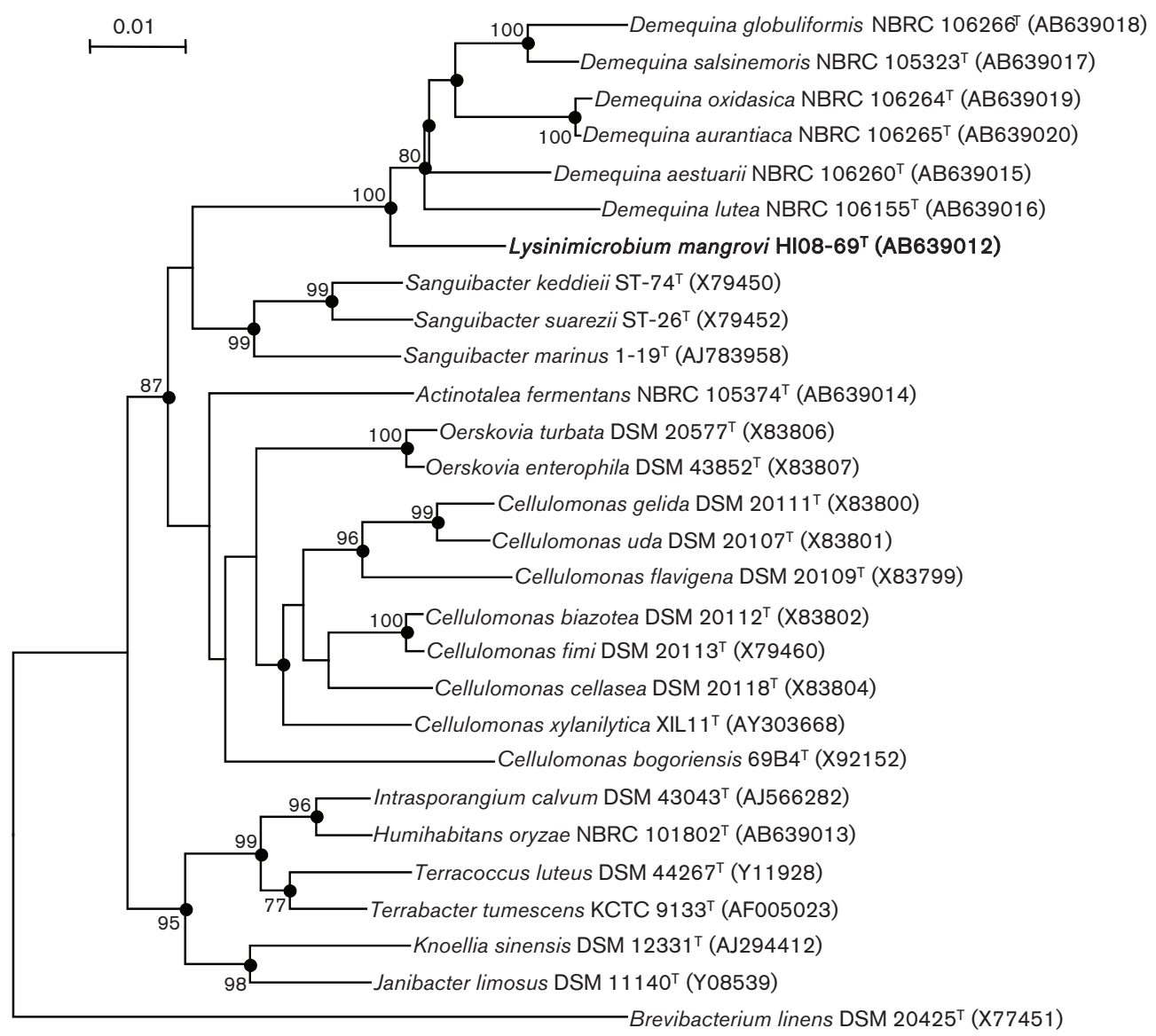

Fig. 2. A neighbour-joining phylogenetic tree based on 16S rRNA gene sequences, showing the relationship between strain HI08-69 $9^{\top}$ and its closest taxonomic neighbours. Brevibacterium linens DSM $20425^{\top}$ was used as the outgroup. Bootstrap values $(>70 \%)$ based on 1000 replicates are shown at branch nodes. Filled circles indicate that the corresponding nodes were also recovered in the trees generated with the maximum-likelihood and maximum-parsimony algorithms. Bar, 0.01 substitutions per nucleotide position.

at position 1 of the peptide subunit. Arabinose, galactose and mannose were detected as the cell-wall sugars. The only isoprenoid quinone detected was demethylmenaquinone DMK- $9\left(\mathrm{H}_{4}\right)$. The major cellular fatty acids were anteiso- $\mathrm{C}_{15: 0}(47.4 \%)$, anteiso- $\mathrm{C}_{17: 0}(16.8 \%)$ and $\mathrm{C}_{16: 0}$ $(11.8 \%)$ but iso- $\mathrm{C}_{16: 0}(7.9 \%), \mathrm{C}_{14: 0}(6.6 \%)$, anteiso- $\mathrm{C}_{15: 1}$ A $(5.0 \%), \mathrm{C}_{15: 0}(2.7 \%)$ and iso- $\mathrm{C}_{15: 0}(1.8 \%)$ were also detected. The predominant polar lipids were diphosphatidylglycerol, phosphatidylglycerol, phosphatidylinositol and an unidentified (phosphorus-free) polar lipid. Minor or trace amounts of phosphatidylinositol mannoside, an unidentified phosphoglycolipid, two unidentified glycolipids and three unidentified (phosphorus-free) polar lipids (Fig. S1, available in IJSEM Online) were also detected. The genomic DNA $\mathrm{G}+\mathrm{C}$ content of the novel strain was $71.7 \mathrm{~mol} \%$.

In the phylogenetic analysis based on $16 \mathrm{~S}$ rRNA gene sequences, strain HI08-69 ${ }^{\mathrm{T}}$ formed a monophyletic cluster with members of the genus Demequina irrespective of the treeing algorithm that was employed. In the neighbour-joining tree, the branch corresponding to this cluster was supported by a bootstrap value of $100 \%$ (Fig. 2). The predominant menaquinone of the novel strain was demethylmenaquinone DMK-9 $\left(\mathrm{H}_{4}\right)$ - the diagnostic isoprenoid quinone of the genus Demequina. It is this menaquinone that permits the current members of the genus Demequina to be distinguished from those of other genera within the suborder Micrococcineae. However, the peptidoglycan of strain HI08- $69^{\mathrm{T}}$ was of the A4 $\alpha$ type, with L-lysine as the diagnostic cell-wall diamino acid, whereas the peptidoglycan of each member of the genus Demequina is reported to be of the A4 $\beta$ type, with L-ornithine as the diagnostic diamino acid (Yi et al., 2007). In terms of its peptidoglycan, therefore, strain HI08-69 ${ }^{\mathrm{T}}$ appears to be distinct from the current members of the genus Demequina. The chemotaxonomic characteristics of strain $\mathrm{HI} 08-69^{\mathrm{T}}$ that allow it to be distinguished from its closest phylogenetic neighbours are summarized in Table 1. Based on the chemotaxonomic and phylogenetic data, strain $\mathrm{HI} 08-69^{\mathrm{T}}$ represent a novel 


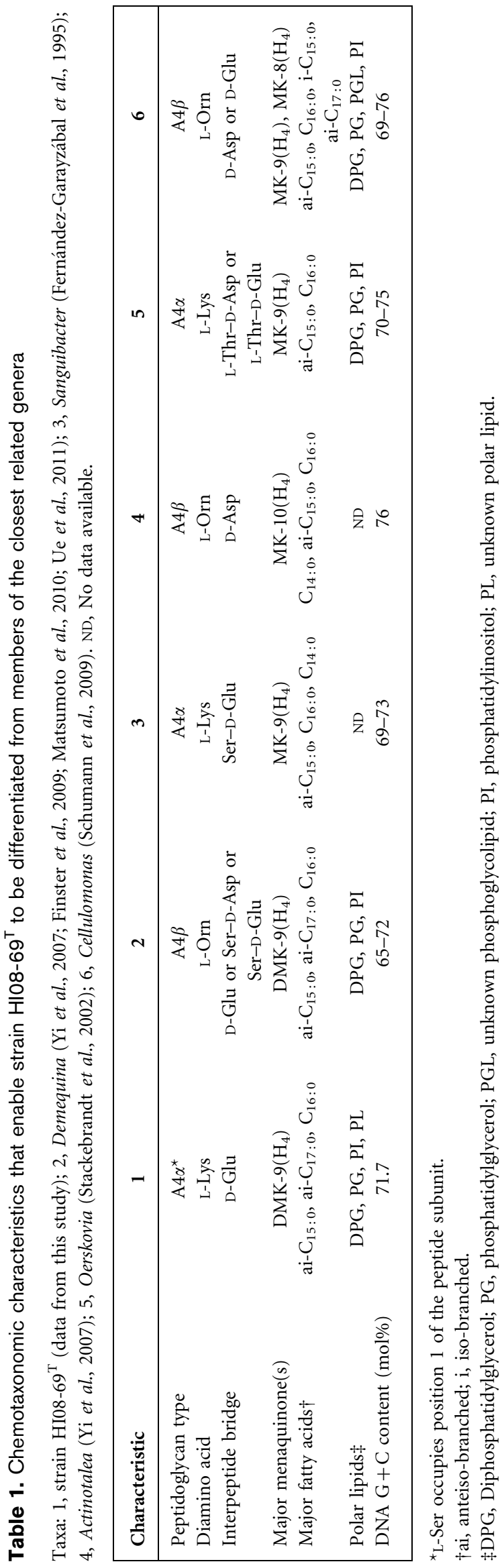

species of a new genus for which the name Lysinimicrobium mangrovi gen. nov., sp. nov. is proposed.

\section{Description of Lysinimicrobium gen. nov.}

Lysinimicrobium (Ly.si.ni.mi.cro'bi.um. N.L. n. lysinum lysine; N.L. neut. n. microbium microbe; N.L. neut. n. Lysinimicrobium a microbe with lysine in the cell wall).

Cells are Gram-staining-positive, facultatively anaerobic and non-spore-forming and exhibit a rod-to-coccus cycle. The cell-wall peptidoglycan is of the A4 $\alpha$ type and contains Llysine as the diagnostic diamino acid, with an L-serine residue at position 1 of the peptide subunit. The major cell-wall sugars are arabinose, galactose and mannose. The predominant menaquinone is DMK- $9\left(\mathrm{H}_{4}\right)$ and the principal polar lipids are diphosphatidylglycerol, phosphatidylglycerol, phosphatidylinositol and an unknown polar lipid. The major cellular fatty acids are anteiso- $\mathrm{C}_{15: 0}$, anteiso- $\mathrm{C}_{17: 0}$ and $\mathrm{C}_{16: 0}$. Phylogenetically, the genus Lysinimicrobium belongs to the family Demequinaceae within the suborder Micrococcineae. The type species is Lysinimicrobium mangrovi.

\section{Description of Lysinimicrobium mangrovi sp. nov.}

Lysinimicrobium mangrovi (man.gro'vi. N.L. gen. neut. n. mangrovi of a mangrove, referring to the isolation of the type strain from the rhizosphere of a mangrove).

Displays the following properties in addition to those given for the genus. Cells of exponentially growing cultures are rodshaped $(0.4-0.6 \times 1.0-3.0 \mu \mathrm{m})$ while stationary-phase cells are oval to coccoid $(0.5-0.6 \times 0.5-1.0 \mu \mathrm{m})$. Cells are nonmotile. Catalase-positive and oxidase-negative. Colonies are pale yellow, circular, transparent and smooth. Grows at 15$28{ }^{\circ} \mathrm{C}$ (optimum $28{ }^{\circ} \mathrm{C}$ ) and $\mathrm{pH}$ 6.0-9.0 (optimum between $\mathrm{pH} 7.0$ and $\mathrm{pH} 8.0)$. Growth occurs with $\mathrm{NaCl}$ at $0-7 \%(\mathrm{w} / \mathrm{v})$ (optimum $0 \%$ ) but not at $10 \%(\mathrm{w} / \mathrm{v})$. Acid is produced from amygdalin, L-arabinose, arbutin, D-cellobiose, D-fructose, Dgalactose, gentiobiose, D-glucose, glycogen, D-lactose, Dmaltose, D-mannose, L-rhamnose, D-ribose, salicin, starch, D-sucrose, D-trehalose and D-xylose. Positive result in tests for leucine arylamidase, $\beta$-galactosidase and $\alpha$ - and $\beta$-glucosidase activities but negative result for alkaline phosphatase, esterase (C4), esterase lipase (C8), lipase (C14), valine arylamidase, cysteine arylamidase, trypsin, chymotrypsin, acid phosphatase, phosphohydrolase, $\alpha$-galactosidase, $\beta$-glucuronidase, $N$ acetyl- $\beta$-glucosaminidase, $\alpha$-mannosidase, $\alpha$-fucosidase, pyrazinamidase, pyrrolidonyl arylamidase, arginine dihydrolase, lysine decarboxylase, ornithine decarboxylase, tryptophan deaminase and urease activities. $\mathrm{H}_{2} \mathrm{~S}$ and indole are not produced. Aesculin is hydrolysed but gelatin is not. Nitrate is not reduced. The interpeptide bridge of the cell-wall peptidoglycan is D-glutamic acid. The major cellular fatty acids are anteiso- $\mathrm{C}_{15: 0}$, anteiso- $\mathrm{C}_{17: 0}$ and $\mathrm{C}_{16: 0}$, while iso$\mathrm{C}_{16: 0}, \mathrm{C}_{14: 0}$, anteiso- $\mathrm{C}_{15: 1} \mathrm{~A}, \mathrm{C}_{15: 0}$ and iso- $\mathrm{C}_{15: 0}$ are found in minor amounts.

The type strain, HI08-69 ${ }^{\mathrm{T}}\left(=\mathrm{NBRC} 105856^{\mathrm{T}}=\mathrm{DSM} 24868^{\mathrm{T}}\right)$ was isolated from the rhizosphere of a mangrove growing on 
Iriomote Island, Japan. The genomic DNA G + C content of the type strain is $71.7 \mathrm{~mol} \%$.

\section{Acknowledgements}

We are grateful to Ms Chiaki Komukai (NBRC) for her excellent technical assistance. This study was supported in part by a research grant from the Institute for Fermentation, Osaka (IFO).

\section{References}

Chun, J., Lee, J.-H., Jung, Y., Kim, M., Kim, S., Kim, B. K. \& Lim, Y.-W. (2007). EzTaxon: a web-based tool for the identification of prokaryotes based on $16 \mathrm{~S}$ ribosomal RNA gene sequences. Int J Syst Evol Microbiol 57, 2259-2261.

Felsenstein, J. (1981). Evolutionary trees from DNA sequences: a maximum likelihood approach. J Mol Evol 17, 368-376.

Felsenstein, J. (1985). Confidence limits on phylogenies: an approach using the bootstrap. Evolution 39, 783-791.

Fernández-Garayzábal, J. F., Dominguez, L., Pascual, C., Jones, D. \& Collins, M. D. (1995). Phenotypic and phylogenetic characterization of some unknown coryneform bacteria isolated from bovine blood and milk: description of Sanguibacter gen. nov. Lett Appl Microbiol 20, 6975.

Finster, K. W., Herbert, R. A., Kjeldsen, K. U., Schumann, P. \& Lomstein, B. A. (2009). Demequina lutea sp. nov., isolated from a high Arctic permafrost soil. Int J Syst Evol Microbiol 59, 649-653.

Fitch, W. M. (1971). Toward defining the course of evolution: minimum change for a specific tree topology. Syst Zool 20, 406-416.

Hamada, M., lino, T., Iwami, T., Harayama, S., Tamura, T. \& Suzuki, K. (2010). Mobilicoccus pelagius gen. nov., sp. nov. and Piscicoccus intestinalis gen. nov., sp. nov., two new members of the family Dermatophilaceae, and reclassification of Dermatophilus chelonae (Masters et al. 1995) as Austwickia chelonae gen. nov., comb. nov. J Gen Appl Microbiol 56, 427-436.

Matsumoto, A., Nakai, K., Morisaki, K., Ōmura, S. \& Takahashi, Y. (2010). Demequina salsinemoris sp. nov., isolated on agar media supplemented with ascorbic acid or rutin. Int J Syst Evol Microbiol 60, 1206-1209.
Nozawa, Y., Sakai, N., Arai, K., Kawasaki, Y. \& Harada, K. (2007). Reliable and sensitive analysis of amino acids in the peptidoglycan of actinomycetes using the advanced Marfey's method. J Microbiol Methods 70, 306-311.

Saitou, N. \& Nei, M. (1987). The neighbor-joining method: a new method for reconstructing phylogenetic trees. Mol Biol Evol 4, 406425.

Sasser, M. (1990). Identification of bacteria by gas chromatography of cellular fatty acids, MIDI Technical Note 101. Newark, DE: MIDI Inc.

Schleifer, K. H. \& Kandler, O. (1972). Peptidoglycan types of bacterial cell walls and their taxonomic implications. Bacteriol Rev 36, 407-477.

Schumann, P., Kämpfer, P., Busse, H. J., Evtushenko, L. I. \& Subcommittee on the Taxonomy of the Suborder Micrococcineae of the International Committee on Systematics of Prokaryotes (2009). Proposed minimal standards for describing new genera and species of the suborder Micrococcineae. Int J Syst Evol Microbiol 59, 1823-1849.

Stackebrandt, E., Breymann, S., Steiner, U., Prauser, H. N. W., Weiss, N. \& Schumann, P. (2002). Re-evaluation of the status of the genus Oerskovia, reclassification of Promicromonospora enterophila (Jáger et al. 1983) as Oerskovia enterophila comb. nov. and description of Oerskovia jenensis sp. nov. and Oerskovia paurometabola sp. nov. Int J Syst Evol Microbiol 52, 1105-1111.

Tamura, K., Peterson, D., Peterson, N., Stecher, G., Nei, M. \& Kumar, S. (2011). MEGA5: molecular evolutionary genetics analysis using maximum likelihood, evolutionary distance, and maximum parsimony methods. Mol Biol Evol 28, 2731-2739.

Thompson, J. D., Gibson, T. J., Plewniak, F., Jeanmougin, F. \& Higgins, D. G. (1997). The CLUSTAL_X windows interface: flexible strategies for multiple sequence alignment aided by quality analysis tools. Nucleic Acids Res 25, 4876-4882.

Ue, H., Matsuo, Y., Kasai, H. \& Yokota, A. (2011). Demequina globuliformis sp. nov., Demequina oxidasica sp. nov. and Demequina aurantiaca sp. nov., actinobacteria isolated from marine environments, and proposal of Demequinaceae fam. nov. Int J Syst Evol Microbiol 61, 1322-1329.

Yi, H., Schumann, P. \& Chun, J. (2007). Demequina aestuarii gen. nov., sp. nov., a novel actinomycete of the suborder Micrococcineae, and reclassification of Cellulomonas fermentans Bagnara et al. 1985 as Actinotalea fermentans gen. nov., comb. nov. Int J Syst Evol Microbiol 57, 151-156. 